\title{
Language Planning and Policy for Equal Footing and Justice in Federal Nepal
}

\author{
Lekhnath Yadav \\ Pulchowk Campus, Institute of Engineering, Tribhuvan University, Kathmandu, Nepal \\ Corresponding author: yadhunitz@gmail.com
}

Received: Nov 22, 2017 Revised: Dec 10, $2017 \quad$ Accepted: Dec 15, 2017

\begin{abstract}
The present article makes an analysis drawing on research and the available literature of the language planning policy for equal footing and justice in federal Nepal. Language planning in Nepal has been largely dominated by the political scenario of Nepal. Nepal has focused on poverty reduction in all of its national plans and policies since 1990. The discourse of 'development' in late capitalism is largely dominated by economic perspective. It invokes the globalization, a free market economy where corporate power addresses the needs of educational and economic policies and planning to address the needs of the global market, rather than focusing on the everyday local needs of people. However, the ideology of development - as - economic - growth disregards social justice and equity. Nepal's educational policies, largely driven by donors, embracing the global ideology. The ideology of language planning is problematic as the minority is doomed to remain in the verge of getting marginalized. In federal Nepal, English language needs to be taught as a subject, rather than used for the medium of instruction in order to bring each and every rank and file on the equal footing. As such the language planning in Nepal under the federal system should be based on the principle of social justice that ensures equality in educational opportunities.
\end{abstract}

Key words: planning, policy, minority, equal footing, justice

\section{Introduction}

According to [1] 125 caste/ethnic groups, among which the Chhetris and the Hill Brahmans consists of $29 \%$ of the population. The ten most numerous caste/ethnic groups constitutes $69 \%$ of the population in total. The remaining $31 \%$ of the population comprises 115 castes and ethnic groups. The Census also reports that 123 languages are spoken by the various ethnic and caste groups. It shows that Nepali and Maithili are the mother tongues of more than $56 \%$ of the population of the country, while just ten languages are the mother tongues of $88 \%$ of the population (Table 1). The remaining $12 \%$ of the population shares 113 mother tongues between them.

Although the existence of multiple languages in Nepal has long been recognized, there have been many shifts of policy concerning their recognition and usage within the education system. The first education plan [8] adopted a policy of language transfer, whereas the second education plan [10] proposed Nepali as (Ek bhasa ek desh) the medium of instruction in public schools, as did subsequent education plans [13]. It was only after the advent of democracy in 1990 that language 
issues in education came to the forefront. Consequently, the constitution of the Kingdom of Nepal (1990; Article 3:18:2) and the subsequent education plans [10] advocated mother tongue education $[7,8,9,10]$. With the Jomtein Declaration (1990) and Dakar Framework for Action (2000), the Government of Nepal endorsed the Education for All (EFA) program (2004-09) to ensure equity in quality basic education for all Nepalese children. As a strategy, the EFA program adopted the use of students' mother tongue as the medium of instruction from grade one to three in a monolingual situation while from the grade four onward the medium of instruction is Nepali as a strategy for the transitional bilingual education. It has decided to translate textbooks for Social Studies and Arithmetic into five mother tongues: Maithili, Newari, Awadhi, Limbu, and Tamang, as a followup action for Mother Tongue (MT) teaching at primary level education $[8,9,10,11,12]$. Similarly, the Basic and Primary Education Project, Phase I [7], has adopted seven languages: Newari, Maithili, Tharu, Awadhi, Limbu, Tamang, and Bhojpuri, and are introduced at primary level as optional subjects. This measure proved to be a landmark towards the introduction of mothertongue instruction. Accordingly, teaching/learning materials (text-books) were also designed and introduced. Later, five other mother-tongues, Sherpa, Chamling, Bantawa, Magar, and Gurung, are introduced [7, 15]. Altogether, twelve languages (out of the nineteen languages, based on personal communication with the government officials of Nepal) have so far been introduced as optional subjects in the different primary schools of more than 17 districts [10].

Table 1: Caste/ethnic groups and mother tongues in Nepal

\begin{tabular}{|l|l|l|l|}
\hline Caste/ethnic groups & \% of population & Mother tongues & \% of Population \\
\hline Chhetri & 16.6 & Nepali & 44.6 \\
\hline Hill Brahman & 12.2 & Maithili & 11.7 \\
\hline Magar & 7.1 & Bhojpuri & 6.0 \\
\hline Tharu & 6.6 & Tharu & 5.8 \\
\hline Tamang & 5.8 & Tamang & 5.1 \\
\hline Newar & 5.0 & Newar & 3.2 \\
\hline Kami & 4.8 & Bajjika & 3.0 \\
\hline Musalman & 4.4 & Magar & 3.0 \\
\hline Yadava & 4.0 & Doteli & 3.0 \\
\hline Rai & 2.3 & Urdu & 2.6 \\
\hline 115 other groups & 31.2 & 113 other languages & 12.0 \\
\hline Total: 125 groups & 100.0 & $\begin{array}{l}\text { Total: 123 mother } \\
\text { tongues }\end{array}$ & 100.0 \\
\hline
\end{tabular}

Source: Central Bureau of Statistics. (2011).

\section{Literature Review}

\subsection{What is a Language Policy?}

A strategy of action adopted with regard to the usage of language or languages by relevant people is known as a language policy. Language polices are purposefully designed to gain betterment in all aspects of lives. So, we can say language policy is multidimensional. Language policy has been an area of interest for many scholars. Preeminent works on language policy has been done by Charles Ferguson, Haugen, Heinz Kloss, Joan Rubin, and Richard Baldauf. Similarly, People like Schiffman, MCarty, Spolsky, Ricento, has also done a lot in the area of language policy. There are certain factors which affect the framing of language policy i.e. socio-linguistic settings, attitude of the language speakers, the strength of the political set up, etc. If the speaker of a language 
develops a positive attitude towards his/her own language s/he can change or modify the existing language policy of that society. Therefore, language policies can be modified over time. Whether it is implicit or explicit it is present everywhere. Good language policies are always needed for the effective working of a nation and language policy cannot be studied without knowing about language planning. For an effective language policy, good language planning is equally important. The need for a language policy is there at different levels. Like: For official use of language (e.g. Administration, law, etc.), for regional level of language, for wider communication (mass media) use of language, for International communication use of languages etc. For all these purposes we need to choose a language and sometimes the need is to develop that language. Planning involves a choice that is made on the basis of a conscious effort to predict the consequences of the proposed alternatives. The goals of language planning differ from one nation to other and from one organization to other. Sometimes language planning is done for assimilating the languages i.e. the dominant language of the society is forced on native speakers of other languages. So they are assimilationist in nature. Some are done for maintaining linguistic pluralism i.e. multilingualism is recognized and supported. Other goals of language planning are standardization, language revitalization, language reform, language maintenance, etc. Planning can be either seen as management of language or manipulation of language. Most of the time language planning is governed by power and politics. Cooper says, language planning is a "deliberate effort to influence the behavior of others with respect to acquisition, structure or functional allocation of their language codes." Various sociolinguists divided the process of language planning into various steps. The general sub-division is of: policy formation, codification, elaboration and implementation. To these sub-processes Eastman added two more namely language choice and evaluation. The process of language choice is never neutral. Choice inevitably means selection and selection is always at the cost of rejection. On the background of various questions language choice can be understood. For example, who is choosing which under what circumstances? This shows the power dynamics working in the selection. The question of choice, covertly takes note of who is being eliminated and with whom, is the pressure group. In the selection process various economic, political, sociological considerations work. So planning should be so that most of the languages get benefit from it.

\subsection{Benefits of Language Planning}

Jernudd is of the opinion,

"Language planning can result in providing several benefits to society. Firstly it provides certain degree of linguistic homogeneity, it can allow for quicker and better communication and consequent increase in the standard of living. Second, language planning in so far as it provides a common means of communication can result in greater equalities of participation."

The language planning may prove to be beneficial if it is implemented earnestly, it can provide opportunities to all of its people to have equal economic and political power, but if it is against its spirit, it may lead to serious consequences such as 'power struggle' 'language movements' and 'language riot'. Jernudd quoted in Mckay further says,

"A final benefit of language planning is that by promoting the use of particular language it can foster a sense of national consciousness thus strengthening the political unity of the country."

The language serves as an integrative symbol because it binds people with one national identity. 


\subsection{Strategy for Language Planning}

Cooper has identified three major types of language planning: Status planning, corpus planning and acquisition planning. Although all three are interlinked yet they address a different social issue. 'Status planning is linked to the official recognition which national governments attach to various languages especially in case of minority languages and to authoritative attempts to extend or restrict language use in various contexts----. It includes issues like designation. If the language(s) of instruction in schools and decisions regarding whether and in which languages ballots may be used. Whereas, Corpus, planning involves activities such as coining news terms, reforming spellings, and modification of old ones, or the selection from alternative forms in a spoken or written code ---------- The third major type of language planning, is proposed as language acquisition planning, which follows from this definition: Language policy-making involves decisions concerning the teaching and use of language, and their careful formulation by those empowered to do so, for the guidance of others.' The impacts of language planning are multidimensional. In countries where hundreds of languages are spoken, they face a very complex situation for the selection of the official or national language, because the decision to impose a certain language would lead to gain or loss of the status of language. In this context I mention the three language formula in India which is linguistically and culturally pluralistic society, about 1064 languages are spoken. Therefore, the selection of a language was complex job. However the Three Language Formula was developed to give the way to the country from conflicting situation. Though it is a compromise between the demands of the various pressure groups by designating Hindi and English as an official language, the government has saved the country from a language controversy. Similarly, Pakistan has a same sociolinguistic background yet the language issue has not been resolved yet. In case of English, the corpus planning in an important issue in terms of what strategy of Language to be promoted. The issues of varieties are more important in courtiers where English has some official status, such as South Africa, Philippine, Israel, Singapore, India and Pakistan. The question is that how the mother tongues could be flourished with imperialism of English in the world. Therefore, the postmodernism in language planning can promise, postmodern intellectual inquiry started to turn back on itself, to question how we come to think as we do why we construct particular visions of reality, in whose interests supposed norms, values, and givens operate. Postmodernism, then, is a philosophical questioning of many of the foundational concepts of received canons of knowledge. Postmodern thought can generally be viewed as anti-essentialism, anti-foundationalism, and opposed to grand narratives. Thus, it calls into question any claims to overarching truths such as "human nature," "enlightenment,' or "emancipation"; it makes us skeptical about talk of reality, truth, or universality. Postmodernism rejects unity, totalization, transcendental concepts, or a belief in disinterested knowledge.

\subsection{English Language in Nepal}

Language planning and policy has passed through enormous critical phases in the history of Nepal since the establishment of Durbar School (Jung Bahadur had established a school at the first time in Nepal after he came back from England to make their family members perfect in English.) to till now the Federal Nepal and its language planning. In Nepal, English was taught as a foreign language from 1854, when Durbar High School was established. However, it was only in 1971 that the "Nepal National Education Plan 1971" formally recognized English as a foreign language along with some other foreign languages such as Chinese, French, Hindi, Japanese, Russian, and Tibetan. Since then, English was being taught from grade four to graduate level courses as a foreign language in Nepalese educational institutes and universities [3,5]. After restoration of 
the multiparty system in 1990, the government of Nepal made the provision for teaching English language from grade one in the place of grade four in 2004. Gradually it would be used as a second language in the Nepalese education system. However, due to perceived inadequacies of the public education system to teach English as a foreign language in particular, parents have invested heavily in private tutoring or language institutes to provide English education to their children [3]. Regarding the scope of English, [6] says, "English is the mother tongue of more than 300 million people in the world, about 3000 million people use it as a second language and around 200 million speak English as a foreign language in the universe". Importance of English language is due to its international use. It is a fact that a vast knowledge of the universe has been recorded in this language. In this modern age when electronic media has widely spread all over the world, it is imperative to have the knowledge of this language because it is the medium of communication and a person lacking the knowledge of this language cannot get awareness of the universal knowledge. Institute of Engineering has been using communication English lab for making the Engineers factory ready, so that, the engineers could display their technical subject's competency easily in foreign land. English is also used as a lingua franca and code switching which is status marker of the speaker. Now, Nepal needs to nullify its past 'one nation, one language' policy, not only to sustain its rich linguistic diversities but also to maximize economic gains through linguistic and cultural heritages of its multi-ethnic societies in a globalized context. Therefore, two languages, or still better, three languages policy could serve the best in order to maximize the learning opportunities inside the class room.

\subsection{Federalism and Language Policy}

There are broadly two concepts of the system of government: Unitary \& Federal. Nepal practiced the unitary system of government throughout its recorded history. However, it was realized that it was not effective for the development and unity of the country. This was visibly expressed by the people during the People's Movement-II in 2062/63 BS. The course of history got changed in 2063 BS. People raised voices for a federal system of government. Nepal was then declared as the Democratic Federal Republic by the Interim Constitution-2063 BS. Now, Nepal is in the process of making a 'New Nepal' on the federal concept. According to part 1, Article 6 of the Constitution, all the languages have been speaking in Nepal are the languages of the nation. However, SubArticle 1 of Article 7 maintains that Nepali language written in the Devanagari script shall be the official language of Nepal. Sub-Article 2 of the same Article mentions that a State may, by the State law, determine one or more than one languages of the nation used by a majority of people within the state as its official language (s) in addition to Nepali. The large majority of population is responsible for seven provincial language but the right of minority people to compete in globalized world does not appear equal [4].

\subsection{Foreign Influence}

In some parts of India, mostly in Hindi speaking states (e.g., UP, Bihar, MP, and Rajasthan), English is being taught as a foreign language, while in some other states, mostly in Southern India, English is being taught as a second language. According to [7], "many minority language children continue to speak their mother tongue at home, but learn to read and write in the dominant regional language... against the principle of learning in one's mother tongue contained within the spirit of the 3-formula policy." Nonetheless, implementation of multilingualism is not that easy in India, given the place of the English language at all levels of education. Though English has become indigenized in India like other English speaking countries like Nigeria and Singapore [5], it is 
still a highly contentious issue in Indian society and in politics. Referring to the English language education in India, the [7] states that English is in India today a symbol of people's aspiration for quality in education and a fuller participation in national and international life.

Its colonial origins now forgotten or irrelevant, its initial role in independent India, tailored to high education (as a 'library language,' a 'window on the world'), now felt to be insufficiently inclusive socially and linguistically, the current state of English stems from its overwhelming presence on the world stage and the reflection of this in the national arena (p. 3). However, the Position Paper also acknowledges that "English does not stand alone. It needs to find its place along with other Indian languages [7].

\section{Methodology}

\subsection{Qualitative Method}

According to [2] a research methodology or strategy is determined by the nature of the research question and the subject being investigated. As a result the research format used in an investigation should be seen as a tool to answer the research question. A qualitative research approach was chosen as the methodology because this approach reinforces an understanding and interpretation of the available literature. This article aims at exploring and understanding the meanings constructed throughout the available literatures. The study does not aim to provide the ultimate truth about the research topic but rather to investigate a particular way of looking at and deriving meaning on the phenomenon under investigation. This study is guided by the following research questions:

How the minority people get their linguistic rights?

Which language formula does suit in the New Nepal?

\section{Results and Discussion}

Keeping in view the forgoing arguments, facts and statements related to the linguistic scenario of Nepal, it is high time for the academicians to provide the foresight and vision on the future language planning and policies of the country. It is also very important to note that the whole energy of the country at present is geared to the election and formation of constitutions that will also be faced with resolving the linguistic debates and conflicts of the country with the very neat and clean language policy $[14,15]$. The public opinion is that there is need of multilingual classes for cognitive development of the students. Where the Medium of Instruction should be broaden according to the global demand. As English Language has its deeper impact all over the world and Nepal gives high priority to the tourism for the economic development. So that, all the citizens should have the good understanding in English Language. MLE is seen as a "two-way" bridge, such that learners gain the ability to move back and forth between their mother tongue and other tongue(s) rather than simply a transitional literacy program where reading through the mother tongue is abandoned at some stage in the education $[3,10,11]$. We should maintain English language rather than Nepali as the language for academic growth and excellences, medium of instructions in the schools, colleges, and universities as well as language to be used as medium of writing in the Competitive Examinations inside and outside the country. We cannot blink to the realities of the globalization and inclusiveness. The CBS reports stand witness to the fact that $90 \%$ of the high-officials of Nepal belong to the Nepali language speakers as their mother tongue. This has seriously damaged and threatened the growth and development of non-Nepali speakers' communities [1]. 


\section{Conclusion}

English is being taught and learned around the world as a second language today. In seven different provinces, the large majority of population is responsible for provincial language for the instruction but what with the minority of the population and their medium of instruction aren't they deprived from the equal footing and justice to reach up to the global community. If the provincial language and the Nepali language is planned for the official language, it would fail to provide equal footing and justice for minority people. So, what if the English language is planned as the second language where English language would be simultaneously with mother tongues. So, it is high time the language planner provided the language planning and management for equal footing and justice which English only can promise. It is imperative that we make provisions for equal footing and justice in every sector of life. Today's reality is that English has been part of our education system for more than a century, yet, English is beyond the reach of most of our young people, which makes highly unequal access in several aspects of lives. The time has come for us to teach English our students, English as a language for every sector of life for building an inclusive society and transforming federal Nepal into a knowledgeable global-society. There should not be double colonization in any aspect of lives in the federal Nepal.

\section{References}

[1] CBS (2011), National Population and Housing Census, National Report. Central Bureau of Statistics, HMG/N, National Planning Commission Secretariat, Thapathali, Kathmandu.

[2] Denzin KN and Lincoln YS (1994), Hand book of qualitative research. New Delhi: The Sage

[3] Giri RA (2010), Cultural anarchism: The consequences of privileging languages in Nepal. Journal of Multilingual and Multicultural Development, 31(1) : 37-41.

[4] Government of Nepal (2072), Constitution of Nepal. Kathmandu, Nepal: Government of Nepal.

[5] Kachru B (2005), Asian Englishes beyond the cannon. Hong Kong: Hong Kong University Press.

[6] Krystal D (2003), English as a global language. New York: Cambridge.

[7] NCERT (2006), National Council of Educational Research and Training, National Focus Group Position Paper on Teaching of English. New Delhi: NCERT.

[8] Nepal National Education Planning Commission (1956), Education in Nepal: Report of the Nepal education planning commission. Kathmandu, Nepal: His Majesty's Government.

[9] Phyak PB (2011), Beyond the façade of language planning for Nepalese primary education: monolingual hangover, elitism and displacement of local languages? Current Issues in Language Planning

[10] Phyak P, Rai N, Rai M and Rai VS (2011), Multilingual education in Nepal: Hearsay and reality? A report. Paper commissioned for UNESCO. Kathmandu: UNESCO.

[11] Taylor SK (2010), MLE policy and practice in Nepal: Identifying the glitches and making it work. In Heugh K \& Skutnabb-Kangas T (Eds.), Multilingual education works: From the periphery to the centre (pp. 204-223). New Delhi: Orient Black Swan.

[12] Toba S, Toba I and Rai NK (2005), Diversity and endangerment of languages in Nepal. Kathmandu, Nepal: UNESCO.

[13] Wood HB (1987), Nepal diary, 1953-1962. Tillamook, OR: American Nepal Education Foundation.

[14] Yadav L (2013), Language planning policy. Pustakalaya Aawaj 6(5): 33-37.

[15] Yadava YP (2007), Linguistic Diversity in Nepal: Perspectives on Language Policy. International Seminar on Constitutionalism and Diversity in Nepal (pp. 1-18). Kathmandu, Nepal. 